\title{
Paisagem, turismo ecológico, florística e uso da flora rupícola da Serra do Jatobá, Paraíba, Brasil
}

\section{Cattleya do Monte Pessoa Felix ${ }^{1}$, Leonardo Pessoa Felix ${ }^{2}$, Erton Mendonça de Almeida ${ }^{3}$, Camilla Marques de Lucena ${ }^{4}$ e Reinaldo Farias Paiva de Lucena ${ }^{5}$}

${ }^{1}$ Universidade Federal da Paraíba. Centro de Exatas e da Natureza. Programa de Pós-Graduação em Desenvolvimento e Meio Ambiente. João Pessoa-PB, Brasil (CEP 58051-900).

${ }^{2}$ Universidade Federal da Paraíba. Centro de Ciências Agrárias. Areia-PB, Brasil (CEP 58397-000).

${ }^{3}$ Usina da Arte. Parque Artístico-Botânico. PE-99, km 10. Água Preta-PE, Brasil (CEP 55550-000).

${ }^{4}$ Instituto de Educação Superior da Paraíba (IESP). Rodovia BR-230, km 14, S/№. Cabedelo-PB, Brasil (CEP 58109-303).

5Universidade Federal da Paraíba. Centro de Exatas e da Natureza. Departamento de Sistemática e Ecologia. João Pessoa-PB, Brasil (CEP 58051-900). E-mail: rfplnal@gmail.com.

Resumo. A Serra do Jatobá constitui um monólito localizado a $10 \mathrm{~km}$ do Município de Serra Branca. Destaca-se do relevo suavemente ondulado da região, com uma cobertura vegetal composta principalmente por plantas rupícolas. Neste trabalho foi realizado um levantamento florístico, paisagístico e dos usos atuais e potenciais da flora desse local. Também foi levantada a ocorrência de espécies raras e seu potencial para uso como planta ornamental. 0 afloramento apresenta diferentes microambientes, destacando-se sulcos, fendas e tanques ou caldeirões, todos resultantes da atividade erosiva, caracterizados pela presença de espécies exclusivas. Foi levantado um total de 41 espécies distribuídas por 33 gêneros e 20 famílias localmente exclusivas. A análise da paisagem e do componente florístico confirmou o potencial deste afloramento para uso em atividades de turismo ecológico e de aventura. Das 41 espécies levantadas, 21 têm diversas utilizações atuais e potenciais referidas pela literatura, especialmente em revistas de medicina, farmácia, etnobotânica e fitoquímica. Dentre estas, 11 espécies foram referidas como medicinais seguidas por outros usos, forragem e tóxicas. Mandevilla dardanoi foi a única espécie rara do afloramento, sendo conhecida anteriormente apenas para o Estado de Pernambuco. Ophioglossum aff. nudicaule é possivelmente uma nova espécie e, juntamente com a ocorrência de uma espécie rara, sugere que a Serra do Jatobá deve ser considerada área prioritária para a conservação. Além disto, o turismo ecológico poderá ser uma alternativa viável que contribuirá para a
Recebido:

$04 / 05 / 2019$

Aceito:

$24 / 07 / 2019$

Disponível on line:

$25 / 07 / 2019$

Publicado:

$31 / 08 / 2019$

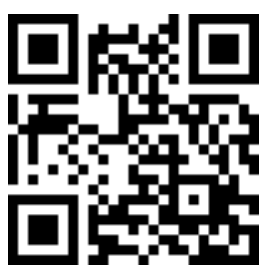

Acesso aberto

() 0000-0002-6126-3440 Cattleya do Monte Pessoa Felix 
manutenção da biodiversidade, podendo ser uma nova alternativa econômica para as comunidades do entorno.

Palavras-chave: Inselberg; Etnobotânica; Uso sustável; Especiação; Caatinga.

Abstract. Landscape, ecological tourism, floristic and use of rupicolous flora of Serra do Jatobá, Paraíba, Brazil. Serra do Jatobá is a monolith localized about $10 \mathrm{~km}$ from the municipality of Serra Branca, and represents a landscape that stands out from the slightly undulating relief of that region, with a vegetation composed mainly of rupicolous plants. In this work was done a floristic and landscape survey, with the current and potential uses of outcrop flora. In addition, it was survey the occurrence of rare species, and flowering or showy species with potential use as ornamental. The outcrop presents different formation of microhabitats, including grooves, crevices and pools or cauldrons, because of the erosive activity, where unique species occur in each of these microhabitats. A total of 41 species were found, distributed among 33 genera and 20 locally exclusive families. The analysis confirmed the potential of this outcrop for ecotourism and adventure activities. From the 41 species surveyed, 21 have different uses reported in the literature, especially in medical, pharmaceutical, ethnobotanical and phytochemical journals. Eleven species were referred as medicinal, followed by other uses, forage and poison. Mandevilla dardanoi was the only rare species found at the outcrop, previously recorded only for the State of Pernambuco. Ophioglossum aff. nudicaule possibly is a new species, and the occurrence of rare and new species for science suggests that the Serra do Jatobá should be considered a priority area for conservation, making the ecotourism a viable alternative for the Biodiversity maintenance, and a new economic alternative for the local communities.

Keywords: Inselberg; Etnobotanic; Sustainable use; Speciation; Caatinga.

\section{Introdução}

Até o século XVIII, a paisagem era observada apenas pelo seu aspecto visual e só mais recentemente passou a ser vista como um recurso passível de produzir ganhos financeiros via atividades turísticas. A paisagem passou a ter importância fundamental, por constituir o componente visual que levará o viajante a divulgar esse recurso via contatos pessoais, ou servirá como pano de fundo para o marketing turístico (Castro, 2006; Chiu et al., 2014).
(D) $0000-0001-9202-9828$ Leonardo Pessoa Felix

D) 0000-0001-8033-5334

Erton Mendonça de Almeida

D) 0000-0002-5126-8969

Camilla Marques de Lucena

(1) 0000-0003-4775-7775 Reinaldo Farias Paiva de Lucena 
mação (Woodside e Martin, 2008). É necessário aprofundar o conhecimento da paisagem, visando a identificar a preferência do turista por determinados padrões paisagísticos (Song e Guo, 2008).

No semiárido da Paraíba, afloramentos rochosos conhecidos como inselbergues, apresentam elevado potencial para o ecoturismo, embora seus componentes físicos e biológicos não sejam perfeitamente conhecidos.

Inselbergues (do alemão inse, ilha; berge, montanha), são ilhas de rochas inseridas no interior do continente formadas geralmente por monólitos graníticos e gnáisicos, resultantes da esfoliação esferoidal (Barthlott e Porembski, 2000). São ambientes diferenciados do entorno, com uma vegetação claramente distinta formada por plantas de várias famílias, incluindo Orchidaceae, Araceae, Bromeliaceae, bem como Pteridófitas, muitas delas raras e de importância ornamental (Safford e Martinelli, 2000). o gênero Ameroglossum, endêmico de inselbergues da região Nordeste (Fischer et al., 1999), por exemplo, possui apenas duas espécies conhecidas, uma delas descrita recentemente (Almeida et al., 2016). Por isso, inselbergues são considerados áreas importantes para a conservação e prioritárias para a criação de futuras unidades de conservação. Apesar disso, muitos afloramentos são explorados como pedreiras, podendo ocasionar erosão genética e perda de espécies ainda desconhecidas, como a nova espécie ainda não descrita de Ameroglossum endêmica do Município de Santo Antônio, no Rio Grande do Norte (Almeida, 2016).

Além de importantes depositários da biodiversidade, os inselbergues exercem fascínio em povos de todo o mundo, como os morros do Pão de Açúcar e do Corcovado, que são verdadeiros cartões postais do Brasil, ou o Morro Uluru, praticamente um símbolo da paisagem australiana (Waternon, 2015). Na Região Nordeste, vários afloramentos como o Morro do Pai Inácio na Bahia (Pedreira e Bonfim, 2002), Monte do Galo no Rio Grande do Norte (Porpino, 2004), são usados para atividades turísticas. Na Paraíba são explorados a Pedra da Boca, em Araruna (Cavalcanti, 2009), e o Lajedo de Pai Mateus, em Cabaceiras (Andrade et al., 2016).

A vegetação dos afloramentos da Paraíba é conhecida apenas por listas florísticas e taxonômicas (Porto et al., 2008; Silva et al., 2015), embora abordagens envolvendo seus usos atuais e potenciais possam contribuir para subsidiar decisões voltadas para uso e gestão destes espaços, para a conservação da paisagem e seu desenvolvimento sustentável (Paula et al., 2015).

Neste trabalho foram estudados aspectos físicos e florísticos da Serra do Jatobá, Município de Serra Branca, Paraíba, buscando identificar seus usos atuais e potenciais, visando ao uso sustentável e à conservação da flora local.

\section{Material e métodos}

A Serra do Jatobá está localizada a cerca de $10 \mathrm{~km}$ do Município de Serra Branca, Paraíba, com uma altitude máxima de $763 \mathrm{~m}$, nas coordenadas $07^{\circ} 29^{\prime} 46^{\prime \prime} \mathrm{S}$ e $36^{\circ} 44^{\prime} 36^{\prime \prime} \mathrm{W}$. Trata-se de um afloramento granítico de coloração esbranquiçada, facilmente visualizável a partir da BR-412, à medida que o viajante aproxima-se da cidade de Serra Branca.

Foram realizadas coletas trimestrais, entre os meses de março de 2010 e fevereiro de 2011, através de coletas aleatórias ao longo do afloramento. Foram coletadas plantas em floração e/ou frutificação que foram herborizadas de acordo com os procedimentos rotineiros em herborização (Bridson e Forman, 1998). Exsicatas de com todas as espécies coletadas encontram-se depositados no Herbário Jaime Coelho de Moraes (EAN), da Universidade Federal da Paraíba, no Município de Areia-PB. 
Foram amostradas apenas espécies que ocorriam diretamente na superfície do afloramento, bem como aquelas que se desenvolviam na matéria orgânica acumulada nas fendas da rocha. Espécies que ocorriam concomitantemente na superfície do afloramento, nas imediações ou na sua borda, foram excluídas, buscando-se obter uma listagem de plantas exclusivas do inselbergue. Amostras secas desses materiais foram apresentadas a pessoas da comunidade local com idade acima de 50 anos, as quais foram indagadas sobre seus nomes vernaculares e possíveis utilidades. Além disso, todos os táxons identificados ao nível de espécie tiveram seus usos pesquisados na base de dados do Google Acadêmico (https://scholar.google.com). No caso de uma espécie apresentar o mesmo uso citado em mais de uma referência, optou-se pela citação da fonte bibliográfica mais recente e em revistas com maior índice de impacto (http://www.scijournal.org/).

Todo o material foi identificado através de literatura especializada, comparações com materiais tipos disponibilizadas na internet, materiais previamente identificados e depositados no Herbário EAN, além de comparação com a lista de espécies da flora do Brasil (http://flora dobrasil.jbrj.gov.br/reflora/listaBrasil).

As espécies foram circunscritas de acordo com os limites genéricos aceitos pela Flora do Brasil 2020, em construção (http://floradobrasil.jbrj.gov.br/reflora/l istaBrasil) e para a delimitação das famílias, foi adotado o sistema APG IV (2016).

Durante todas as expedições para coleta foram tomadas fotografias para a documentação dos diferentes aspectos da paisagem da Serra do Jatobá, além do reconhecimento e documentação fotográfica das espécies amostradas. Além disso, foram realizadas entrevistas com moradores da região para avaliar o conhecimento da comunidade local sobre o uso potencial da paisagem como recurso turístico.

\section{Resultado e discussão}

A Serra do Jatobá está localizada a $10 \mathrm{~km}$ do Município de Serra Branca, Paraíba, com uma altitude máxima de $763 \mathrm{~m}$ (Figura 1A). 0 afloramento é constituído por rocha granítica de coloração branca, sulcada pela ação das águas pluviais (Figura 1B), que em vários pontos originou a formação de tanques temporários, ou caldeirões (Figura 1D). Em alguns pontos, a erosão provocou a fratura e o arredondamento das rochas, algumas delas distribuídas pela superfície do afloramento (Figura 1C). Tanques em afloramentos rochosos em regiões secas constituem um recurso tradicionalmente utilizado pelas comunidades locais de regiões semiáridas em todo o mundo (Gnadlinger, 2006), além de desempenhar importante papel como ambiente preferencial para a reprodução de anuros (Wassersug, 1981). São muitas vezes artificialmente ampliados, como ocorre no Curimataú e Agreste da Paraíba, para uso geral pelas comunidades (Almeida e Cabral, 2013). $\mathrm{Na}$ área em estudo, todos os tanques ou caldeirões de pedra apresentaram-se parcialmente soterrados por sedimentos, proporcionando condições para o desenvolvimento de uma flora diferenciada, notadamente pelo registro da única Scrophulariaceae sl do afloramento, Angelonia biflora Benth. (Figura 3E). Em afloramentos africanos, é comum a ocorrência de espécies tipicamente aquáticas ou semiaquáticas dos gêneros Drosera e Utricularia (Porembski et al., 2000), que não foram localizadas na Serra do Jatobá. A formação de microhabitas em afloramentos do semiárido nordestino parece está relacionada à especiação local originando a formação de novos táxons possivelmente relacionados ao isolamento geográfico, pressões de seleção e deriva genética (Almeida et al., 2016). 


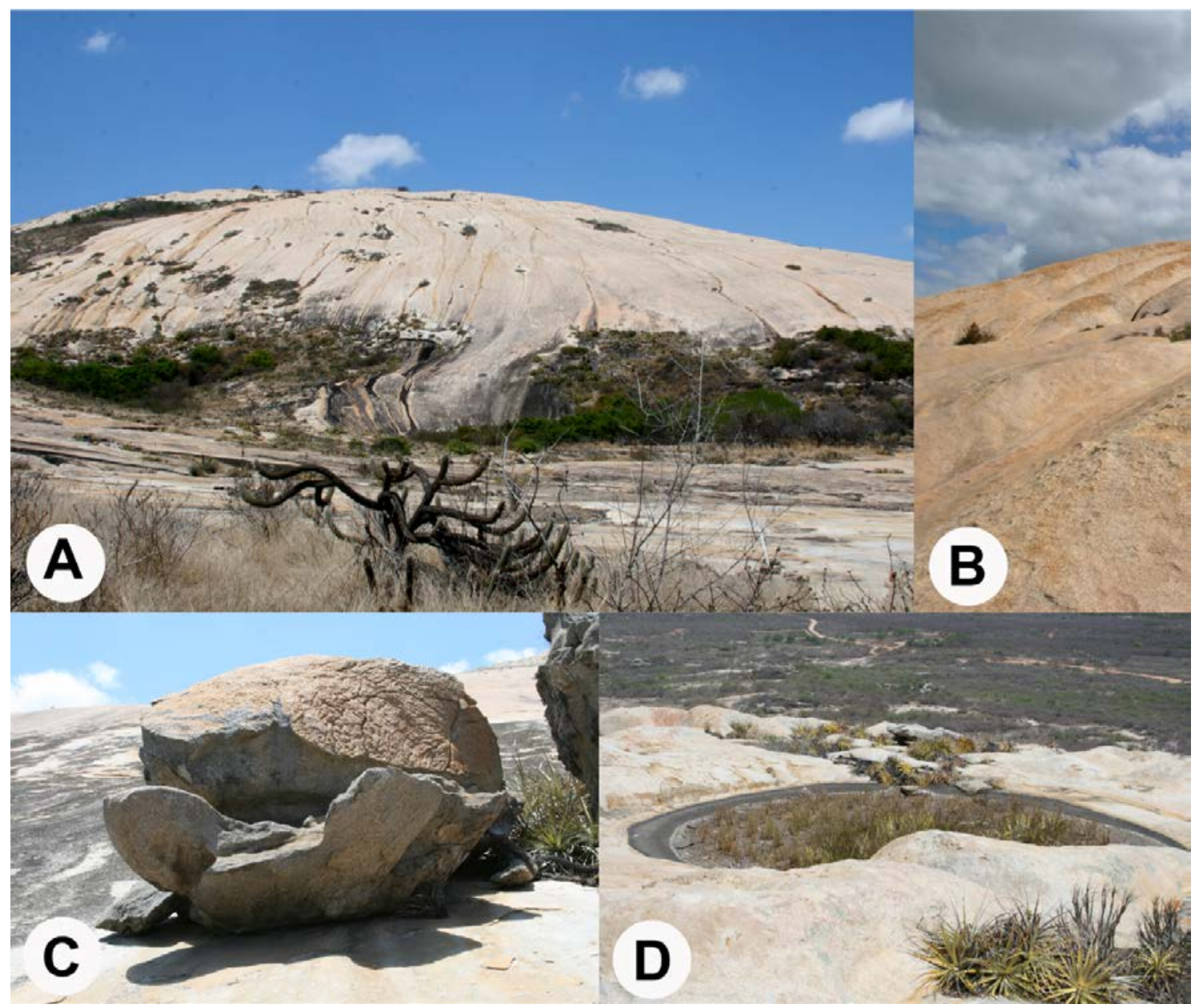

Figura 1. Serra do Jatobá: Aspecto geral e detalhes. A. Vista geral da Serra do Jatobá a partir da base; B. Detalhe dos sucos ocasionados pera erosão pluvial; C. Rochas fragmentadas; D. Vista de um tanque temporário (caldeirão).

Apesar de possuir uma paisagem com beleza cênica privilegiada, a maioria das pessoas da comunidade local entrevistadas não reconheceu o potencial da paisagem como recurso utilizável para o turismo ecológico e uma fonte suplementar de renda. 0 único empreendimento voltado para esse fim nas proximidades da serra, o Bar e Restaurante Refúgio da Serra, encontrava-se desativado durante a realização da pesquisa. Também não foi observada qualquer ação oficial do município que pudesse estimular o turismo em nível regional. Até mesmo a colocação de placas indicativas de acesso a Serra do Jatobá são inexistentes.
Contudo, durante a pesquisa foram encontrados visitantes da zona urbana do próprio município. Quando indagadas sobre o motivo da visitação, as pessoas demonstraram interesse pela beleza cênica do lugar e curiosidade de conhecimento in loco.

Decorrente da formação de micro-habitats, a composição florística da Serra do Jatobá, assim como outros afloramentos da Região Nordeste (França et al., 1997; Porto et al., 2008; Gomes et al., 2011; Pinheiro et al., 2014), é surpreendentemente diversificada. Em levantamento florístico realizado no decorrer desta pesquisa foram reconhecidas um total de 41 espécies 
distribuídas por 33 gêneros e 20 famílias localmente exclusivas do afloramento. A Tabela 1 relaciona todas as espécies coletadas, assim como seus usos potenciais revisados da literatura. Dentre essas espécies algumas se destacaram pelo seu valor ornamental, enquanto outras foram relatadas por pessoas da comunidade local como tendo propriedades tóxicas e medicinais, ou raras e ameaçadas e constituem endemismos regionais (veja comentários abaixo).
Mandevilla dardanoi M.F. Sales et al. (Figura 2A). Espécie descrita há pouco mais de 10 anos, é considerada rara e ameaçada, até então considerada endêmica para afloramentos graníticos do Planalto da Borborema em Pernambuco (Sales et al., 2006). Trata-se de uma espécie bastante ornamental encontrada principalmente na porção superior da Serra.

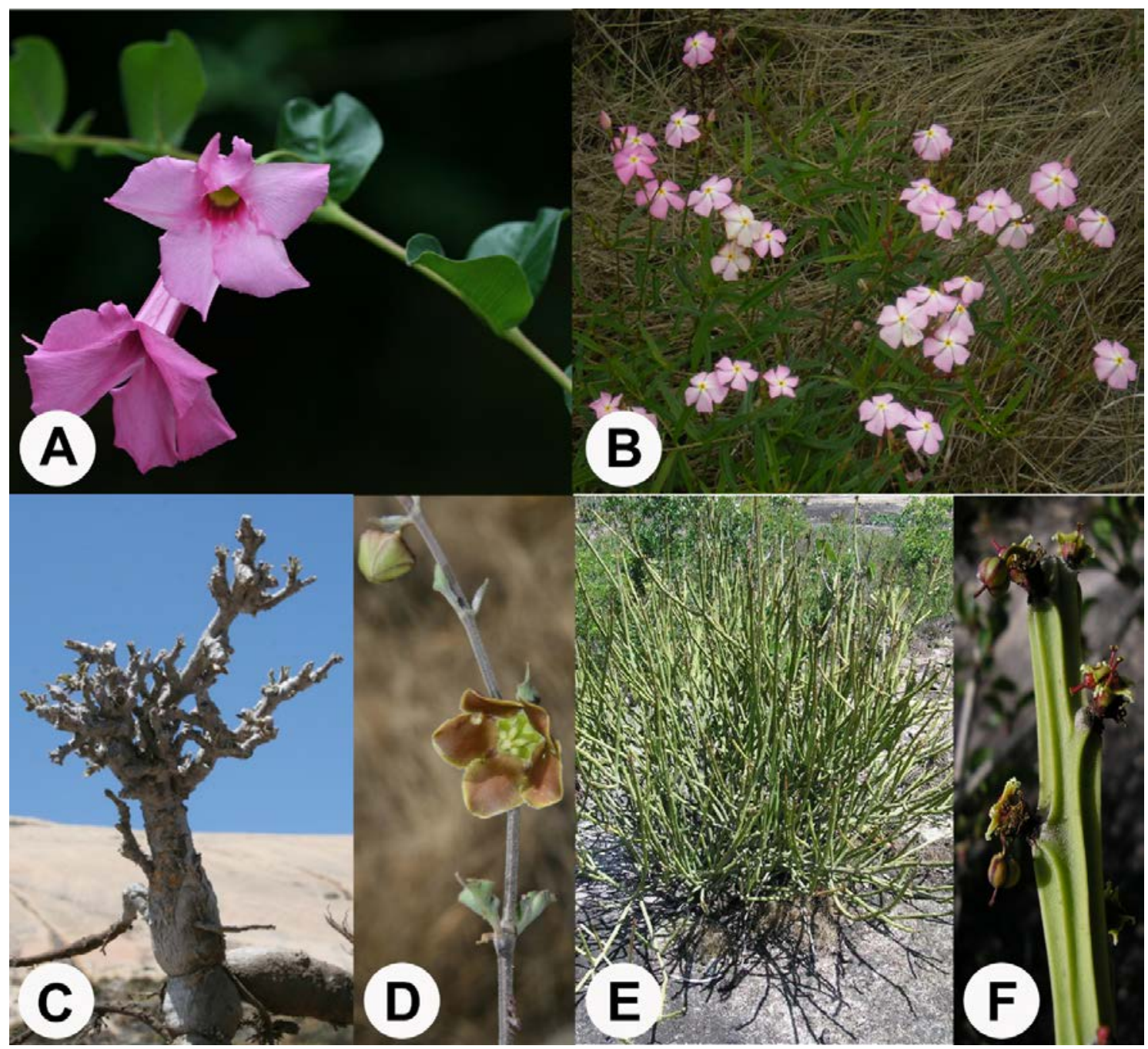

Figura 2. Plantas ornamentais, raras ou de importância econômica da Serra do Jatobá. A. Mandevilla dardanoi. Detalhe de um ramo com flores; B. Mandevilla tenuifolia. Planta florida na época das chuvas; C-C. Marsdenia megalantha. Aspecto vegetativo da planta na estação da seca (C) e ramo florido (D); E-F. Euphorbia phosphorea. Aspecto vegetativo da planta em seu habitat (E) e detalhe do ciátio (F). 
Mandevilla tenuifoia (J.C. Mikan)

Woodson. Descrita originalmente como Echites tenuifolius J.C. Mikan, foi recombinada posteriormente para o gênero Mandevilla por Woodson (1933). Possui um importante potencial para uso como planta ornamental (Figura 2B) e suas raízes podem ser consumidas in natura como alimento pelas comunidades locais.

Marsdenia megalantha Goyder \& Morillo. Descrita em 1994, é uma espécie endêmica da região Nordeste, onde ocorre em afloramentos e ambientes pedregosos, exclusivamente no bioma Caatinga (Goyder e Morillo, 1994). Tem potencial para uso como planta ornamental, especialmente em jardins xéricos (Figura 2C-D). Referida por membros da comunidade local como bastante tóxica para o gado, a espécie exibiu uma toxicidade exacerbada para ruminantes em geral e para suínos, podendo ocasionar sua morte (Geraldo Neto et al., 2013).

Euphorbia phosphorea Mart. (Figura 2E-F). É uma das raras espécies de Euphorbia neotropicais com hábito cactiforme. Compõe, juntamente com mais três outras espécies de habitat rupícola da Região Sudeste, a secção Brasilienses do gênero Euphorbia (Riina et al., 2015). A espécie é cultivada como ornamental, especialmente em jardins xéricos e rupestres.

Luetzelburgia auriculata Mart. (Figura 3 A-B). Conhecida localmente como Pau-pedra, é reconhecida por pessoas da comunidade como tóxica para o gado. Corroborando este conhecimento, um experimento com caprinos, confirmou a toxicidade desta leguminosa, com dose letal a partir de 2,5g/kg de peso vivo (Mello et al,. 2010). Por outro lado, sementes de Pau-pedra possuem lectinas com poderosa atividade anti-inflamatória (Alencar et al., 2010).
Erythrina velutina Willd. (Figura 3 C-D). É uma planta típica da Caatinga, referida para todos os estados do Nordeste, exceto Maranhão (Flora do Brasil 2020, em construção), localmente reconhecida como medicinal. A espécie é amplamente conhecida por sua ação tranquilizante, o que foi confirmado experimentalmente em ratos (Ribeiro et al., 2006). Assim como Luetzelburgia auriculata, a espécie também possui efeito anti-inflamatório comprovado (Marchioro et al., 2005).

Vellozia plicatta Mart. A única espécie de Velloziaceae citada para o estado da Paraíba, conhecida localmente como canela-de-ema, não teve qualquer uso referido pela comunidade local. Trata-se de uma planta com elevado potencial de uso como ornamental, especialmente pelas suas belas, porém efêmeras flores brancas (Figura $3 \mathrm{~F}-\mathrm{H}$ ). Assim como a maioria das Velloziaceae, a canela-de-ema é uma das raras angiospermas tolerante ao dessecamento e, por isso, considerada uma planta poiquilohídrica (Meguro et al., 1977; Kluge e Brulfert, 2000).

Além de apresentar um potencial turístico essencialmente vinculado à beleza da paisagem, o local é propicio a realização de trilhas, rapel, escaladas, trekking, e outras modalidades relacionadas ao turismo de aventura o que é atualmente destacado em sites divulgados por pessoas do município de Serra Branca e imediações (veja em http://serradojatoba.wixsite.com/turism o). A adoção do turismo ecológico e de aventura neste e em outros afloramentos dos Cariris Velhos, poderia representar uma prática conservacionista da paisagem e da flora em geral, além de contribuir para a melhoria da renda das comunidades locais. 


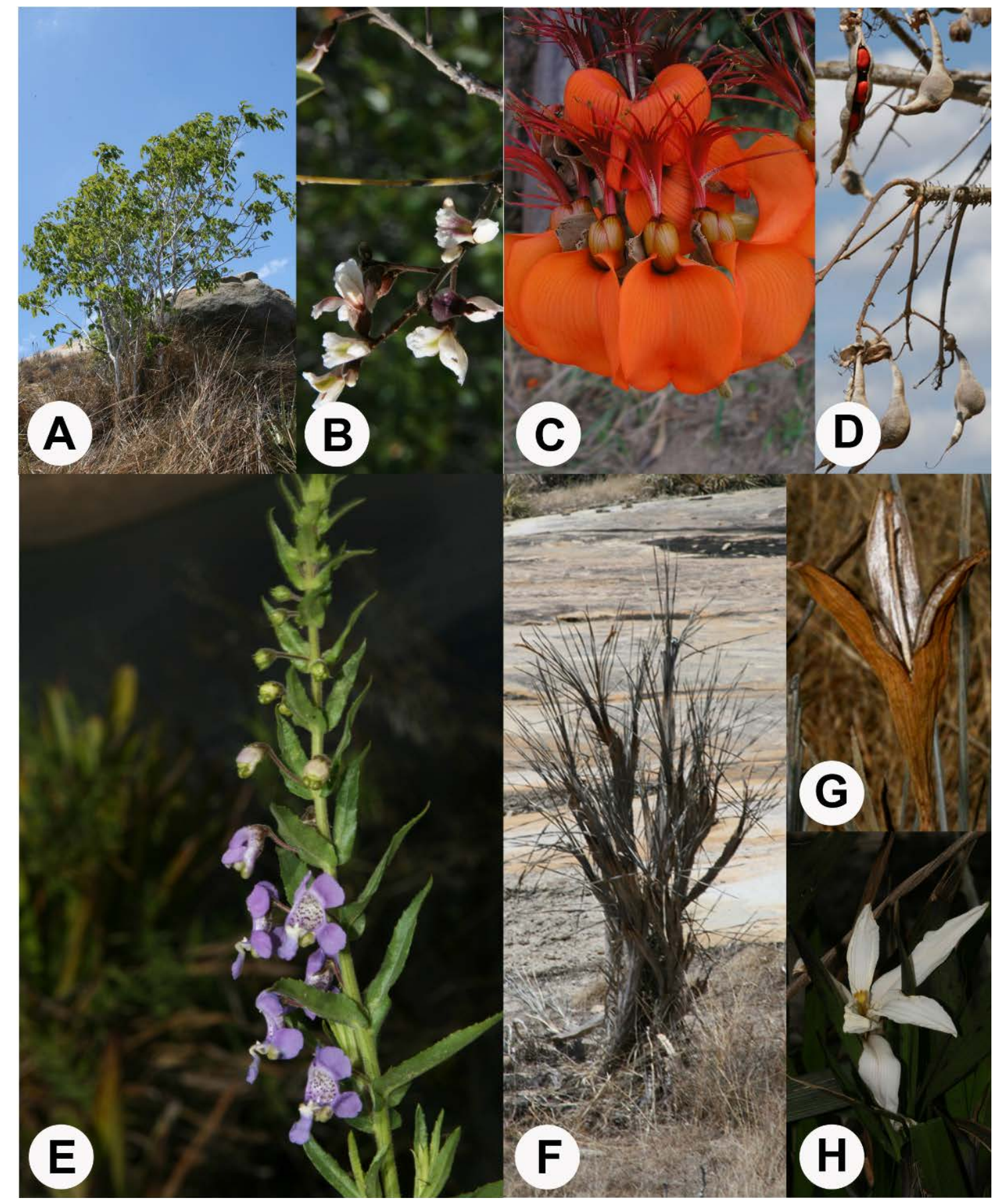

Figura 3. Plantas ornamentais, raras ou de importância econômica da Serra do Jatobá. A-B. Luetzelburgia auriculata. Hábito de crescimento (A) e inflorescência (B). C-D. Erythrina velutina. Flores (C), frutos e sementes (D). E. Ramo florido de Angelonia biflora. F-H. Vellozia plicatta. Planta na estação seca $(F)$, fruto $(G)$ e flor $(H)$.

Dentre as espécies levantadas, Ophioglossum aff. nudicaule, foi a única pteridófita registrada para o afloramento. Curiosamente, uma análise do material depositado no Herbário EAN por um especialista neste grupo de plantas, foi conclusiva de que não se trata de Ophioglossum nudicaule. Seria 
possivelmente, uma nova espécie para a ciência, sendo, entretanto, necessária a realização de trabalhos complementares para descrever esse novo táxon (M. J. M. Christenhusz, comunicação pessoal).

Tabela 1. Lista de espécies rupícolas da Serra do Jatobá, Município de Serra Branca, Paraíba, seus usos atuais e potenciais.

\begin{tabular}{l|l}
\hline Família gênero/espécie & Usos atuais e potenciais \\
\hline Apocynaceae & \\
\hline Mandevilla dardanoi M.F. Sales et al. & \\
\hline M. tenuifolia (J.C. Mikan) Woodson & \\
\hline Marsdenia megalantha Goyder \& Morillo & Tóxica (Geraldo Neto et al., 2013) \\
\hline Bromeliaceae & \\
\hline Aechmea leptantha (Harms) Leme \& J.A. Siqueira & \\
\hline Encholirium spectabile Mart. ex Schult. \& Schult. f. & Antibacteriana (Peixoto et al., 2016) \\
\hline Hohenbergia catingae Ule & \\
\hline Tillandsia recurvata (L.) L. & Anticancerígeno (Lowe et al., 2015) \\
\hline Cactaceae & \\
\hline Melocactus ernestii Vaupel & \\
\hline Pilosocereus chrysostele (Vaupel) Byles \& G.D. Rowley & Forragem (Lucena et al., 2015) \\
\hline P. gounellei F.A.C. Weber) Byles \& Rowley & Diversos (Lucena et al., 2015) \\
\hline P.pachycladus F. Ritter & Diversos (Lucena et al., 2015) \\
\hline Convolvulaceae & \\
\hline Evolvulus elegans Moric. & \\
\hline Euphorbiaceae & \\
\hline Cnidoscolus urens (L.) Arthur & Anti-hemorrágico (Menezes et al., 2013) \\
\hline Croton blanchetianus Baill. & Bactericida, e bacteriostático (Melo et al., \\
\hline Croton sp1. & 2013) \\
\hline Croton sp2. & \\
\hline Jatropha mollissima (Pohl) Baill & Antibotrópico (Gomes et al., 2016) \\
\hline J. ribifolia (Pohl) Baill. & Medicinal, religião (Soares et al., 2013) \\
\hline Euphorbia phosphorea Mart & Ornamental \\
\hline Fabaceae & \\
\hline Senna martiana (Benth.) H.S. Irwin \& Barneby & \\
\hline Erythrina velutina Willd & Antidepressiva (Ribeiro et al., 2006) \\
\hline Luetzelburgia auriculata (Allemão) Ducke & $\begin{array}{l}\text { Tóxica (Mello et al., 2010). anti- } \\
\text { inflamatória (Alencar et al., 2010) }\end{array}$ \\
\hline Crotalaria holosericea Nees \& Mart. & \\
\hline Mimosa paraibana Barneby & Antioxidante (Nunes et al., 2008) \\
\hline Lamiaceae & \\
\hline Hyptis leptostachys Epling & \\
\hline Malpighiaceae & \\
\hline Byrsonima gardneriana A. Juss. & \\
\hline Melastomataceae & \\
\hline Tibouchina gardneri (Naudin) Cogn. & \\
\hline Opphioglossaceae & \\
\hline Ophioglossum aff. nudicaule & \\
\hline Orchidaceae & \\
\hline Cyrtopodium flavum Link \& Otto ex Rchb. f. & \\
\hline & \\
\hline
\end{tabular}


Tabela 1. Continuação.

\begin{tabular}{l|l}
\hline Família gênero/espécie & Usos atuais e potenciais \\
\hline Plantaginaceae & \\
\hline Angelonia biflora Bent. & \\
\hline Rhamnaceae & $\begin{array}{l}\text { Antimicótico (Cruz et al., 2007), } \\
\text { antioxidante e antimicrobiano (Ribeiro } \\
\text { et al., 2013), outros (Lucena et al., 2008) }\end{array}$ \\
\hline Ziziphus joazeiro Mart. & \\
\hline Rubiaceae & Apícola (Silva et al., 2008) \\
\hline Borreria capitata (Ruiz \& Pavon) DC. & $\begin{array}{l}\text { Antirreumátia (Coelho et al., 2006) e } \\
\text { antimicótica (Bolzani et al., 1996) }\end{array}$ \\
\hline Tocoyena formosa (Cham. \& Schltdl.) K Schum & \\
\hline Turneraceae & Apícola (Rodarte et al., 2008) \\
\hline Turnera calyptrocarpa Urb. & Antitumoral (Barbosa et al., 2007) \\
\hline T. chamaedrifolia Cambess. & \\
\hline Velloziaceae & \\
\hline Vellozia plicata Mart. & Analgésico (Oliveira et al., 2015) \\
\hline Verbenaceae & \\
\hline Lippia grata Schauer & \\
\hline Vittaceae & \\
\hline Cissus decidua Lombardi & \\
\hline
\end{tabular}

\section{Conclusões}

A análise da paisagem e composição florística das espécies da Serra do Jatobá, confirma o potencial desse afloramento para uso em atividades de turismo ecológico e de aventura. Do seu componente florístico, aproximadamente, metade tem diferentes usos referidos pela literatura, especialmente em revistas de medicina, farmácia, etnobotânica e fitoquímica. Dentre estas espécies, a maioria foi referida pelo uso como medicinais seguidas por forrageiras e tóxicas. $\mathrm{Na}$ família Apocynaceae, ocorreu à única espécie reconhecidamente rara do afloramento, Mandevilla dardanoi, sendo que o atual registro amplia a área de distribuição do táxon, anteriormente reconhecido apenas para o Estado de Pernambuco. A única pteridófita registrada para o afloramento, Ophioglossum aff. nudicaule, é possivelmente uma nova espécie para a ciência. Materiais dessa mesma espécie coletados em outros afloramentos do estado Paraíba sugerem que esse novo táxon possa ocorrer também em outros afloramentos da Região Nordeste. Todavia, assim como Mandevilla dardanoi, e outras espécies de inselbergues (Ameroglossum, por exemplo), por se tratar de uma espécie rara, sua conservação deverá ser priorizada. Nesse sentido, o desenvolvimento do turismo ecológico para a região, poderá ser uma alternativa viável para a conservação da biodiversidade e como uma nova opção econômica para as comunidades do entorno.

\section{Agradecimentos}

$\begin{array}{lll}\text { CNPq Conselho Nacional de } & \text { de } \\ \text { Desenvolvimento } & \text { Científico }\end{array}$ Tecnológico), à CAPES (Coordenação de Aperfeiçoamento de Pessoal de Nível Superior), ao INSA (Instituto Nacional do Semiárido) pelo auxílio financeiro e apoio com equipamentos e a Felipe Nollet Medeiro de Assis pela correção do Abstract. 


\section{Conflitos de interesse}

Os autores declaram não haver conflitos de interesse.

\section{Referências}

Alencar, N. M. N.; Oliveira, R. S. B.; Figueiredo, J. G.; Cavalcante, I. J. M.; Matos, M. P. V.; Cunha, F. Q.; Nunes, J. V. S.; Bomfim, L. R.; Ramos, M. V. An anti-inflammatory lectin from Luetzelburgia auriculata seeds inhibits adhesion and rolling of leukocytes and modulates histamine and PGE2 action in acute inflammation models. Inflammation Research, v. 59, n. 4, p. 245-254, 2010. https://doi.org/10.1007/s00011-009-0092-9

Almeida, E .M.; Wanderley, A. M.; Nollet, F.; Costa, F. R.; Souza, L. G. R.; Felix, L. P. A new species of Ameroglossum (Scrophulariaceae) growing on inselbergs in Northeastern Brazil. Systematic Botany, v. 41, n. 02, p. 423-429, 2016. https://doi.org/10.1600/036364416X 691740

Almeida, H. A.; Cabral, L. V. Água e desenvolvimento sustentável na zona rural das Microrregiões do Agreste e Curimataú da Paraíba. Revista de Geografia, v. 30, n. 3, p. 82-97, 2013.

Andrade, L. G.; Ramos, N. L.; Morais, L. G. B L. Potencial geoturístico do Semiárido paraibano: um estudo acerca do Município de Cabaceiras/PB. REGNE - Revista de Geociências do Nordeste, v. 2, n. especial, p. 1514-1524, 2016.

APG IV. An update of the Angiosperm Phylogeny Group classification for the orders and families of flowering plants: APG IV. Botanical Journal of the Linnean Society, v. 181, n. 1, p. 1-20, 2016. https://doi.org/ 10.1111/boj.12385

Barbosa, D. A.; Silva, K. N.; Agra, M. F. Estudo farmacobotânico comparativo de folhas de Turnera chamaedrifolia Cambess. e Turnera subulata Sm. (Turneraceae). Revista Brasileira de Farmacognosia, v. 17, n. 3, p. 396-413, 2007. https://doi.org/ 10.1590/S0102-695X2007000300016

Barthlott, W.; Porembski, S. Why study inselbergs? In: Porembski, W.; Barthlott, S. (Ed.). Inselbergs biotic diversity of isolated rock outcrops in tropical and temperate regions. Berlin: Springer-Verlag, 2000. p 1-6.

Bolzani, V. S.; Trevisan, L. M. V.; Izumisawa, C. M.; Yuong, M. C. M. Antifungal iridoids from stems of Tocoyna formosa. Journal of the Brazilian Chemical Society, v. 7, n. 3, p. 157160, 1996. https://doi.org/10.5935/01035053.19960024

Bridson, D.; Forman, L. The herbarium handbook. 3. ed. Kew: Royal Botanic Gardens, 1998.

Castro, C. Narrativas e imagens do turismo no Rio de Janeiro In: Velho, G. (Ed.). Antropologia urbana: cultura e sociedade no Brasil e em Portugal. Rio de Janeiro: Jorge Jahar Editor, 2006. p. 80-88.

Cavalcanti, M. B. Ecoturismo no Bioma Caatinga: o caso do Parque Estadual da Pedra da Boca, Paraíba. Revista Nordestina de Ecoturismo, v. 2, n. 1, p. 25-38, 2009.

Chiu, Y.-T. H.; Lee, W.-I.; Chen, T.-H. Environmentally responsible behavior in ecotourism: Antecedents and implications. Tourism Management, v. 40, p. 321-329, 2014. https://doi.org/10.1016/j.tourman. 2013.06.013

Coelho, V. P. M.; Agra, M. F.; Barbosa, M. R. V. Estudo farmacobotânico das folhas de Tocoyena formosa (Cham. \& Schltdl.) K. Schum. (Rubiaceae). Revista Brasileira de Farmacognosia, v. 16, n. 2, p. 170-177, 2006. https://doi.org/10.1590/S0102695X2006000200007

Cruz, M. C. S.; Santos, P. O.; Barbosa Jr., A. M.; Mélo, D. L.; Alviano, C. S.; Antoniolli, A. R.; Alviano, D. S.; Trindade, R. C. Antifungal activity of Brazilian medicinal plants involved in popular treatment of mycoses. Journal of Ethnopharmacology, v. 111, n. 2, p. 409412, 2007. https://doi.org/10.1016/j.jep. 2006.12.005

Fischer, E.; Vogel, S.; Lopes, A. V. Ameroglossum, a new monopypic genus of Scrophulariacea-Scrophularioideae from Brazil. Feddes Repertorium, v. 110, n. 7/8, p. 529-534, $1999 . \quad$ https://doi.org/ 10.1002 /fedr.19991100713

Flora do Brasil 2020 em construção. Jardim Botânico do Rio de Janeiro. Disponível em: <http://floradobrasil.jbrj.gov.br/>. Acesso em: 11 jan. 2019. 
França, F.; Melo, E.; Santos, C. C. Flora de inselbergs da Região de Milagres, Bahia, Brasil: I. Caracterização da vegetação e lista de espécies de dois inselbergs. Sitientibus, n. 17 , p. $163-184,1997$.

Geraldo Neto, S. A.; Lima, J. M.; Câmara, A. C.; Gadelha, I. C.; Olinda, R. G.; Batista, J. S.; SotoBlanco, B. Spontaneous and experimental poisoning by Marsdenia megalantha Goyder \& Morillo in ruminants and a pig. Toxicon, v. 63, p.116-119, 2013. https://doi.org/ 10.1016/j.toxicon.2012.12.006

Gnadlinger, J. Tecnologias de captação e manejo de água de chuva em regiões semiáridas. In: Kuster, A. Tecnologias apropriadas para terras secas: manejo sustentável de recursos naturais em regiões semiáridas no Nordeste do Brasil. Fortaleza: Fundação Konrad Adenauer, 2006. p. 103122.

Gomes, R.; Costa, K. C. C.; Rodal, M. J. N.; Alves, M. Checklist of angiosperms from the Pedra Furada Municipal Park, Northeastern Brazil. Check List, v. 7, n. 2, p. 173-181, 2011. https://doi.org/10.15560/7.2.173

Gomes, J. A. S.; Félix-Silva, J.; Fernandes, J. M.; Amaral, J. G.; Lopes, N. P.; Egito, E. S. T.; SilvaJúnior, A. A.; Zucolotto, S. M.; FernandesPedrosa, M. F. Aqueous leaf extract of Jatropha mollissima (Pohl) Bail decreases local effects induced by bothropic venom. BioMed Research International, v. 2016, Article ID 6101742, 2016. https://doi.org/ $10.1155 / 2016 / 6101742$

Goyder, D.; Morillo, G. A new species of Marsdenia (Asclepiadaceae) from N.E. Brazil. Asklepios, v. 63, p. 18-20, 1994.

Kluge, M.; Brulfert. J. Ecophysiology of vascular plants on inselbergs. In: Porembski, S.; Barthlott, W. (Ed.). Inselbergs: Biotic diversity of isolated rock outcrops in tropical and temperate regions. Berlin: Springer, 2000. p. $143-176$.

Lowe, H. I. C.; Toyang, N. J.; Watson, C. T.; Ayeah, K. N.; Bryant, J. Antileukemic activity of Tillandsia recurvata and some of its cycloartanes. Anticancer Research, v. 34, n. 7 , p. $3505-3510,2015$.

Lucena, R. F. P.; Nascimento, V. T.; Araújo, E. L.; Albuquerque, U. P. Local uses of native plants in an area of Caatinga vegetation (Pernambuco, NE Brazil). Ethnobotany Research \& Applications, v. 6, p. 3-13, 2008.
Lucena, C. M.; Carvalho, T. K. N.; Ribeiro, J. E. S.; Quirino, Z. G. M.; Casas, A.; Lucena, R. F. P. Conhecimento botânico tradicional sobre cactáceas no semiárido do Brasil. Gaia Scientia, v. 9, n. 2, p. 77-99, 2015.

Marchioro, M.; Blank, M. F. A.; Mourão, R. H. V.; Antoniolli, A. R. Anti-nociceptive activity of the aqueous extract of Erythrina velutina leaves. Fitoterapia, v. 76, n. 7/8, p. 637-642, 2005. https://doi.org/10.1016/j.fitote.2005. 07.002

Meguro, M.; July, C. A.; Bittencourt, M. M. Stress hídrico e alguns aspectos do comportamento fisiológico em Xerophyts plicata Spreng. - Felloziaceae. Boletim de Botânica da Universidade de São Paulo, v. 5, p. 27-42, 1977.

Mello, G. W. S.; Oliveira, D. M.; Carvalho, C. J. S.; Cavalcante, M. V. F. L.; Costa, F. A. L.; RietCorrea, F.; Silva, S. M. M. S. Poisoning of goats by the pods of Luetzelburgia auriculata. Toxicon, v. 55, n. 6, p. 1115-1118, 2010. https://doi.org/10.1016/j.toxicon.2009.12.0 20

Melo, G. F. A.; Costa, A. C. V.; Garino Junior, F.; Medeiros, R. S.; Madruga, M. S.; Queiroga Neto, V. The sensitivity of bacterial foodborne pathogens to Croton blanchetianus Baill essential oil. Brazilian Journal of Microbiology, v. 44, n. 4, p. 1189-1194, 2013. https://doi.org/10.1590/S151783822014005000009

Menezes, Y. A. S.; Félix-Silva, J.; Silva-Júnior, A. A.; Rebecchi, I. M. M.; Oliveira, A. S.; Uchoa, A. F.; Fernandes-Pedrosa, M. F. Protein-rich fraction of Cnidoscolus urens (L.) Arthur leaves: Enzymatic characterization and procoagulant and fibrinogenolytic activities. Molecules, v. 19, n. 3, p. 3552-3569, 2013. https://doi.org/10.3390/molecules19033552

Nunes, X. P.; Mesquita, R. F.; Silva, D. A.; Lira, D. P.; Costa, V. C. O.; Silva, M. V. B.; Xavier, A. L.; Diniz, M. F. F. M.; Agra, M. F. Constituintes químicos, avaliação das atividades citotóxica e antioxidante de Mimosa paraibana Barneby (Mimosaceae). Revista Brasileira de Farmacognosia, v. 18, Suppl., p. 718-723, 2008. https://doi.org/10.1590/S0102695X2008000500015

Oliveira, M. G. B.; Guimarães, A. G.; Araújo, A. A.; Quintans, J. S.; Santos, M. R.; QuintansJúnior, L. J. Cyclodextrins: Improving the therapeutic response of analgesic drugs: A 
patent review. Expert Opinion on Therapeutic Patents, v. 25, n. 8, p. 1-11, 2015. https://doi.org/10.1517/13543776. 2015.1045412

Pedreira, A. J.; Bonfim, L. F. C. Morro do Pai Inácio, BA. Marco morfológico da Chapada Diamantina. In: Schobbenhaus, C. (Ed.). Sítios geológicos e paleontológicos do Brasil. Rio de Janeiro: DNPM, CPRM, SIGEP, 2002. p. 307-312.

Peixoto, R. M.; Lima e Silva, W. E.; Almeida, J. R. G. S.; Branco, A.; Costa, M. M. Antibacterial potential of native plants from the Caatinga Biome against Staphylococcus spp. isolates from small ruminants with mastitis. Caatinga, v. 29 , n. 3, p. 758-763, 2016. https://doi.org/ 10.1590/1983-21252016v29n328rc

Pinheiro, F.; Cozzolino, S.; Draper, D.; Barros, F.; Félix, L. P.; Fay, M. F.; Palma-Silva, C. Rock outcrop orchids reveal the genetic connectivity and diversity of inselbergs of Northeastern Brazil. BMC Evolutionary Biology, 14:49, 2014. https://doi.org/ 10.1186/1471-2148-14-49

Porpino, G. Carnaúba dos Dantas: Terra do Monte do Galo e de grandes músicos. Preá: Revista de Cultura, v. 9, p. 58-68, 2004.

Porembski, S.; Becker, U.; Seine, R. Islands on islands: Habitats on inselbergs. In: Porembski, S.; Barthlott, W. (Eds.). Inselbergs: Biotic diversity of isolated rock outcrops in tropical and temperate regions. Berlin: Springer, 2000. p. 49-68.

Porto, P. A. F.; Almeida, A.; Pessoa, W. J.; Felix, L. P.; Trovão, D. Composição florística de um inselbergue no agreste paraibano, Município de Esperança, Nordeste do Brasil. Caatinga, v. 21, n. 2, p. 214, 2008.

Ribeiro, M. D.; Onusic, G. M.; Poltronieri, S. C.; Viana, M. B. Effect of Erythrina velutina and Erythrina mulungu in rats submitted to animal models of anxiety and depression. Brazilian Journal of Medical and Biological Research, v. 39, n. 2, p. 263-270, 2006. https://doi.org/10.1590/S0100879X2006000200013

Ribeiro, B. D.; Alviano, D. S.; Barreto, D. W.; Coelho, M. A. Z. Functional properties of saponins from sisal (Agave sisalana) and juá (Ziziphus joazeiro): Critical micellar concentration, antioxidant andantimicrobial activities. Colloids and Surfaces A: Physicochemical and Engineering Aspects, v. 436, p. 736-743, 2013. https://doi.org/ 10.1016/j.colsurfa.2013.08.007

Riina, R.; Marques, 0.; Hurbath, F. Euphorbia from Brazil: The succulent section Brasilienses. Euphorbia World, v. 11, n. 3, p. 5-11, 2015.

Rodarte, A. T. A.; Silva, F. O.; Viana, B. F. A flora melitófila de uma área de dunas com vegetação de Caatinga, Estado da Bahia, Nordeste do Brasil. Acta Botanica Brasilica, v. 22, n. 2, p. 301-312, 2008. https://doi.org/ 10.1590/S0102-33062008000200001

Rolim, T. L.; Wanderley, F. T. S.; Cunha, E. V. L.; Tavares, J. F.; Oliveira, A. M. F.; Assis, T. S. Constituintes químicos e atividade antioxidante de Byrsonima gardneriana (Malpighiaceae). Quimica Nova, v. 36, n. 4, p. 524-527, 2013. https://doi.org/10.1590/ S0100-40422013000400007

Safford, H. D.; Martinelli, G. Southeast Brazil. In: Porembski, S.; Barthlott, W (Eds.). Inselbergues: Biotic diversity of isoleted rock outcrops in tropical and temperate regions. Berlin: Springer-Verlag, 2000. p. 339-390.

Sales, M. F.; Kinoshita, L. S.; Simões, A. 0. Eight new species of Mandevilla Lindley (Apocynaceae, Apocynoideae) from Brazil. Novon: A Journal for Botanical Nomenclature, v. 16, n. 1, p. 112-128, 2006.

Silva, R. A.; Evangelista-Rodrigues, A.; Aquino, I. S.; Felix, L. P.; Mata, M. F.; Peronico, A. S. Caracterização da flora apícola do semiárido da Paraíba. Archivos de Zootecnia, v. 57, n. 220, p. 427-438, 2008.

Silva, T. S.; Felix, L. P.; Melo, J. I. M. Bromeliaceae and Orchidaceae on rocky outcrops in the Agreste Mesoregion of the Paraíba State, Brazil. Hoehnea, v. 42, n. 2, p. 345-365, 2015. https://doi.org/10.1590/ 2236-8906-51/2014

Soares, Z. A.; Lucena, R. F. P.; Ribeiro, J. E. S.; Carvalho, T. K. N.; Ribeiro, J. P. O.; Guerra, N. M.; Silva, N.; Pedrosa, K. M.; Coutinho, P. C.; Lucena, C. M.; Alves, C. A. B.; Sousa Júnior, S. P. Local botanical knowledge about useful species in a Semi-Arid Region from Northeastern Brazil. Gaia Scientia, v. 7, n. 1, p. 80-103, 2013.

Song, H.; Guo, W. Tourism demand modelling and forecasting. In: Woodside, A. G.; Martin, D. (Ed.). Tourism management: Analysis, 
behavior and strategy. Cambridge: CABI, 2008. P. 113-128.

Song, H.; Guo, W. Tourism management: Theory, research and pratice. Song, H.; Guo, W. (Ed.). Tourism management: Analysis, behavior and strategy. Cambridge: CABI, 2008. p 1-13.

Wassersug, R. J.; Lum, A. M.; Potel, M. J. An analysis of school structure for tadpoles (Anura: Amphibia). Behavioral Ecology and Sociobiology, v. 9, n. 1, p. 15-22, 1981. https://doi.org/10.1007/BF00299848

Waternon, E. Visuality and its affects: Some new directions for Australian heritage tourism. History Compass, v. 13, n. 2, p. 51-63, 2015. https://doi.org/10.1111/ hic3.12216

Woodson, R. Studies in the Apocynaceae IV: The American genera of Echitoideae. Annals of the Missouri Botanical Garden, v. 20, p. 605-790, 1933. https://doi.org/10.2307/ 2394156 seja devidamente citada. 